\title{
Cellulolytic enzyme expression and simultaneous conversion of lignocellulosic sugars into ethanol and xylitol by a new Candida tropicalis strain
}

\author{
Anu Jose Mattam, Arindam Kuila, Niranjan Suralikerimath, Nettem Choudary, Peddy V. C. Rao \\ and Harshad Ravindra Velankar*
}

\begin{abstract}
Background: Lignocellulosic ethanol production involves major steps such as thermochemical pretreatment of biomass, enzymatic hydrolysis of pre-treated biomass and the fermentation of released sugars into ethanol. At least two different organisms are conventionally utilized for producing cellulolytic enzymes and for ethanol production through fermentation, whereas in the present study a single yeast isolate with the capacity to simultaneously produce cellulases and xylanases and ferment the released sugars into ethanol and xylitol has been described.

Results: A yeast strain isolated from soil samples and identified as Candida tropicalis MTCC 25057 expressed cellulases and xylanases over a wide range of temperatures $\left(32\right.$ and $\left.42^{\circ} \mathrm{C}\right)$ and in the presence of different cellulosic substrates [carboxymethylcellulose and wheat straw (WS)]. The studies indicated that the cultivation of yeast at $42^{\circ} \mathrm{C}$ in pre-treated hydrolysate containing $0.5 \%$ WS resulted in proportional expression of cellulases (exoglucanases and endoglucanases) at concentrations of 114.1 and $97.8 \mathrm{U} \mathrm{g}^{-1} \mathrm{ds}$, respectively. A high xylanase activity $\left(689.3 \mathrm{U} \mathrm{g}^{-1} \mathrm{ds}\right)$ was also exhibited by the yeast under similar growth conditions. Maximum expression of cellulolytic enzymes by the yeast occurred within $24 \mathrm{~h}$ of incubation. Of the sugars released from biomass after pretreatment, $49 \mathrm{~g} \mathrm{~L}^{-1}$ xylose was aerobically converted into $15.8 \mathrm{~g} \mathrm{~L}^{-1}$ of xylitol. In addition, $25.4 \mathrm{~g} \mathrm{~L}^{-1}$ glucose released after the enzymatic hydrolysis of biomass was fermented by the same yeast to obtain an ethanol titer of $7.3 \mathrm{~g} \mathrm{~L}^{-1}$.

Conclusions: During the present study, a new strain of $C$. tropicalis was isolated and found to have potential for consolidated bioprocessing (CBP) applications. The strain could grow in a wide range of process conditions (temperature, $\mathrm{pH}$ ) and in the presence of lignocellulosic inhibitors such as furfural, HMF and acetic acid. The new yeast produced cellulolytic enzymes over a wide temperature range and in the presence of various cellulosic substrates. The cellulolytic enzymes produced by the yeast were effectively used for the hydrolysis of pretreated biomass. The released sugars, xylose and glucose were, respectively, converted into xylitol and ethanol. The potential shown by the new inhibitor tolerant cellulolytic C. tropicalis to produce ethanol or xylitol is of great industrial significance.
\end{abstract}

Keywords: Candida tropicalis, Cellulase, Ethanol, Wheat straw, Xylanase, Xylitol

\section{Background}

Lignocellulosic biofuels are promising alternatives to fossil fuels due to their less polluting nature, renewability

\footnotetext{
*Correspondence: harshadrv@hpcl.in

Bioprocess Group, Hindustan Petroleum Corporation Limited, HP Green R\&D Centre, KIADB Industrial Area, Tarabahalli, Devanagundi, Hoskote, Bengaluru 560067, India
}

and miscibility with conventional transportation fuels. The production of biofuels from biomass comprises a multistep process consisting of unit operations such as biomass pretreatment, enzymatic hydrolysis, fermentation and product separation. During the past two decades, significant research efforts have gone into the optimization and integration of each of these processes 
using a wide variety of biomass and biocatalysts [1]. The information generated through earlier studies has aided in setting up pilot scale facilities for lignocellulosic biofuel production [2].

Notwithstanding the advancements, lignocellulosic biofuel production technologies have not been widely commercialized. The cost of producing ethanol from lignocellulosic biomass is still considered to be higher than from sugar-based feedstock mainly because the cost of processing the biomass is substantial. To minimize the risks, biomass pretreatment processes are usually designed to take in multiple or mixed feedstock which adds up to the cost of its processing [3, 4]. The cost of biomass processing can, however, be controlled by selecting a process which is rapid, requires minimum catalyst (chemicals/enzymes) quantities as well as energy inputs, maximizes catalyst reuse, and results in minimal sugar degradation and inhibitor formation to achieve maximum sugar release through biomass depolymerisation [4-8].

The sugars released from biomass at different stages mainly consist of pentose and hexose monomers. Several industrial strains such as Saccharomyces sp. can convert hexose sugars into ethanol; albeit xylose conversion still remains challenging [9]. Although several wild-type microorganisms are known to convert pentoses into ethanol [10-12], a robust biocatalyst that can be utilized at the industrial levels is yet to be found. Studies from the recent past indicate the development of engineered 'pentose-to-ethanol' converting biocatalysts which may now become the way forward. As an alternative, the xylose sugars generated during biomass hydrolysis can also be fermented into a product with higher value than ethanol such as xylitol, whose co-production will reduce the cost of cellulosic ethanol production $[6,13]$.

Another projected approach to lower the cost of lignocellulosic ethanol production is via consolidated bioprocessing (CBP) with a single microorganism which can produce cellulolytic enzymes for biomass hydrolysis and can ferment the released sugars into ethanol, all together in a single step. However, CBP for cellulosic ethanol production at even the pilot scale remains largely hypothetical mainly due to inherent problems of suboptimal cellulase/xylanase expression or impaired fermentation yields [14]. Due to these reasons, microorganisms expressing cellulolytic enzymes are still not considered as a suitable candidate for carrying out ethanol fermentations and vice versa.

In the present study, a new isolate identified as Candida tropicalis was found to express cellulases and xylanases and convert xylose into xylitol and glucose into ethanol. Preliminary studies were carried out to determine the effects of substrates on cellulase and xylanase production by the yeast. The cellulolytic enzymes produced by the yeast isolate were used for the hydrolysis of pre-treated biomass and sugar hydrolysate was fermented into ethanol. The yeast also showed the ability to aerobically convert xylose into xylitol in the presence of inhibitory compounds. The new yeast isolate is a potential candidate for producing cellulosic ethanol via CBP.

\section{Results and discussion}

A single microorganism that expresses cellulolytic enzymes for hydrolysis of biomass and ferments the released sugars into ethanol and other value added products such as xylitol is of potential interest to the industry. In this study, a new cellulolytic strain was isolated on an agar plate having CMC as the only carbon source. Microscopic examination indicated that the isolate was a yeast and $18 \mathrm{~S}$ rRNA sequencing subsequently confirmed that it was a $C$. tropicalis strain. Since there are hardly any reports about cellulolytic Candida sp. the strain identity was reconfirmed by sequencing the variable D1-D2 domain of the $26 \mathrm{~S}$ rRNA and the internal transcribed spacer (ITS) region of the $5.8 \mathrm{~S}$ rRNA, as these have been projected as more authentic markers for strain identification than $18 \mathrm{~S}$ rRNA $[15,16]$. All the three sequences of MTCC 25057 showed a complete $100 \%$ homology to $C$. tropicalis.

The cellulolytic enzymes produced by the new yeast isolate were used for the hydrolysis of pre-treated wheat straw and the released glucose was converted into ethanol by the same yeast strain. After acid pretreatment of wheat straw, the xylose generated in the hydrolysate could be converted into xylitol or used for producing cellulolytic enzymes. Barring an earlier report related to endoglucanase activities in C. tropicalis cultures after prolonged incubation periods [17] and despite the knowledge about the existence of genes coding for cellulolytic enzymes [GenBank:3636270; 3637086; 8296755, etc.], no other related reports were found.

\section{Tolerance of Candida tropicalis MTCC 25057 to inhibitory compounds}

For utilizing sugars in lignocellulosic hydrolysates, the biocatalyst has to withstand the presence of inhibitory compounds such as furfural, HMF and acetic acid that are usually generated during biomass pretreatment [18]. In the present study, wheat straw procured from local sources was subjected to pretreatment with $0.2 \%(\mathrm{v} / \mathrm{v})$ phosphoric acid as optimized previously in the authors' laboratory [19]. The lignocellulosic hydrolysate contained glucose $(\sim 0.5 \% \mathrm{w} / \mathrm{v})$ and xylose $(\sim 1.5 \% \mathrm{w} / \mathrm{v})$ as the major components along with negligible quantities of inhibitory 
Fig. 1 Effect of a different inhibitors (furfural, HMF, acetate) concentration, $\mathbf{b}$ temperature and $\mathbf{c}$ initial pH on growth of Candida tropicalis. The error bar range represents standard deviation from mean, $t$ test significance level $p<0.005$

compounds such as furfural and $\operatorname{HMF}(\sim 0.01 \% \mathrm{w} / \mathrm{v})$. Several reports indicate the formation of acetic acid during biomass pretreatment, although the same was not detected during our studies. Preliminary studies for determining the tolerance of the new yeast to higher concentrations of furfural, HMF as well as acetic acid, which might get generated during harsher pretreatments indicated that the Candida isolate tolerated furfural, HMF and acetate concentrations of $1.5,2$ and $2 \mathrm{~g} \mathrm{~L}^{-1}$, respectively (Fig. 1a). Further increase in the levels of furfural, HMF and acetic acid resulted in a gradual lowering of biomass densities (Fig. 1a). A recent report related to the fermentative capacities of $C$. tropicalis isolate to produce ethanol and xylitol in hydrolysate, indicated that the yeast could not function beyond furfural, HMF and acetate levels higher than $0.23,0.15$ and $1.37 \mathrm{~g} \mathrm{~L}^{-1}$ respectively [20]. In comparison, the new yeast isolate under investigation was found to be more tolerant to commonly occurring lignocellulosic inhibitors.

In addition to ethanol toxicity, osmotic stress and $\mathrm{pH}$ variations [21, 22], commercial scale ethanol bioprocesses also encounter increased temperatures during summer seasons during which the yeast is supposed to perform as normally as under optimal conditions [23]. We observed during our studies that cell growth of the new yeast isolate was not affected over a wide range of temperatures $\left(32-42{ }^{\circ} \mathrm{C}\right)$ and $\mathrm{pH}(4-10)$ (Fig. 1b, c). Also, the cellulase and xylanase production by the yeast isolate remained largely unaffected over a wide range of temperatures $\left(32-42^{\circ} \mathrm{C}\right)$.

\section{Cellulase and xylanase production by Candida tropicalis MTCC 25057}

Earlier reports indicate that the temperature of incubation and the nature of substrates mainly affect cellulolytic enzyme production [24, 25]. Experiments were designed to determine cellulase (endoglucanase and exoglucanase) and xylanase production by the new yeast strain at different temperatures ( 32 and $42{ }^{\circ} \mathrm{C}$ ), cellulosic substrates (CMC and WS) and at different concentrations (w/v) of $0.5,1$ and $2 \%$ (Fig. 2) in pretreated lignocellulosic hydrolysate. Maximum endoglucanase activity of $98 \pm 2 \mathrm{U} \mathrm{g}^{-1} \mathrm{ds}$ was obtained using $0.5 \%$ WS at $42{ }^{\circ} \mathrm{C}$ (Fig. 2a). Similarly, the exoglucanase production in hydrolysate containing $0.5 \%$ wheat straw was maximum $\left(114 \pm 3 \mathrm{U} \mathrm{g}^{-1} \mathrm{ds}\right)$ at $42{ }^{\circ} \mathrm{C}$ (Fig. 2b). At lower incubation temperature of $32{ }^{\circ} \mathrm{C}$, the endo and exoglucanase levels in
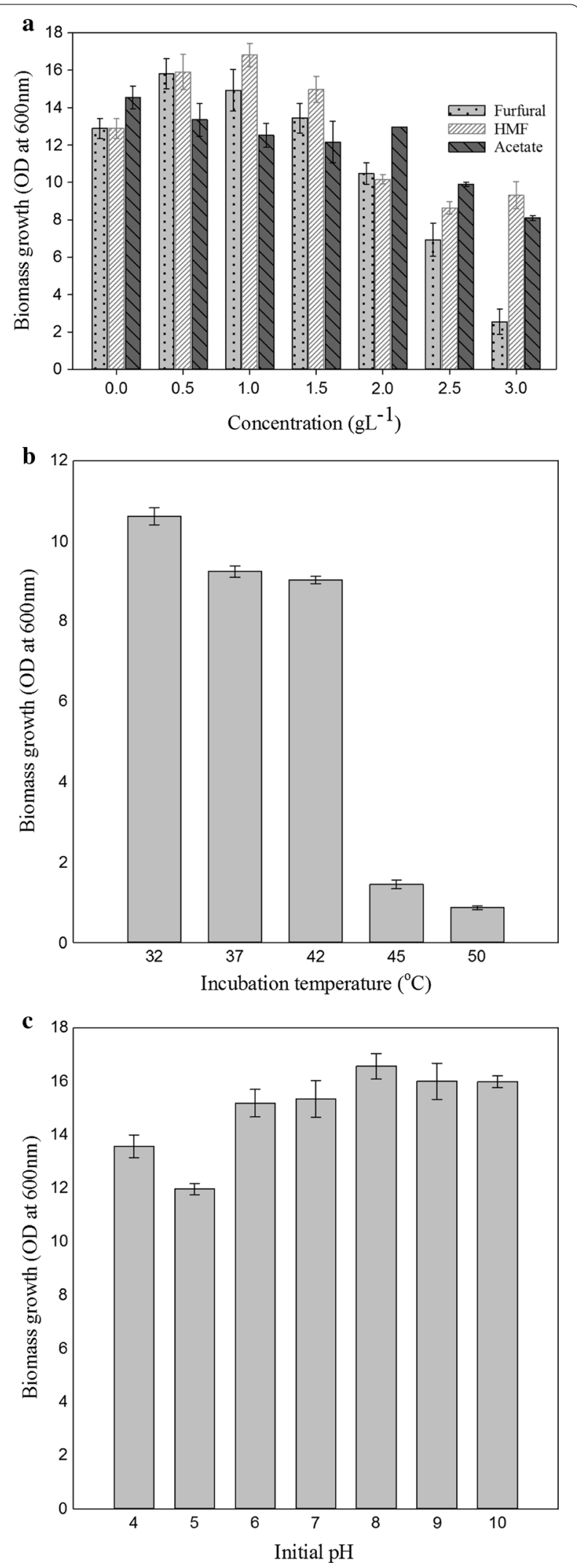
hydrolysate were lower than their corresponding levels at $42{ }^{\circ} \mathrm{C}$ with both the substrates and at all the concentrations tested (Fig. 2a, b).

Earlier studies have indicated that cellulolytic enzyme blends with approximately equal exoglucanase and endoglucanase activities are more suitable for optimal biomass hydrolysis [26]. In this work, we observed that amongst the two temperatures tested, maximum endoglucanase (Fig. 2a) and exoglucanase (Fig. 2b) activities were obtained at $42{ }^{\circ} \mathrm{C}$, while $0.5 \%$ WS was found to be a more suitable cellulosic substrate. The ratios of endo and exoglucanases at $42{ }^{\circ} \mathrm{C}$ were proportional and their activities were comparable to the previously reported cellulase expression levels by well-known enzyme producer strains such as Trichoderma and Aspergillus sp. [27-29].

Regarding xylanases, the activity obtained at $32{ }^{\circ} \mathrm{C}$ was marginally higher $\left(825 \pm 14 \mathrm{U} \mathrm{g}^{-1} \mathrm{ds}\right)$ than that obtained at $42{ }^{\circ} \mathrm{C}\left(689 \pm 17 \mathrm{U} \mathrm{g}^{-1} \mathrm{ds}\right)$ with $0.5 \%$ WS (Fig. 2c) in
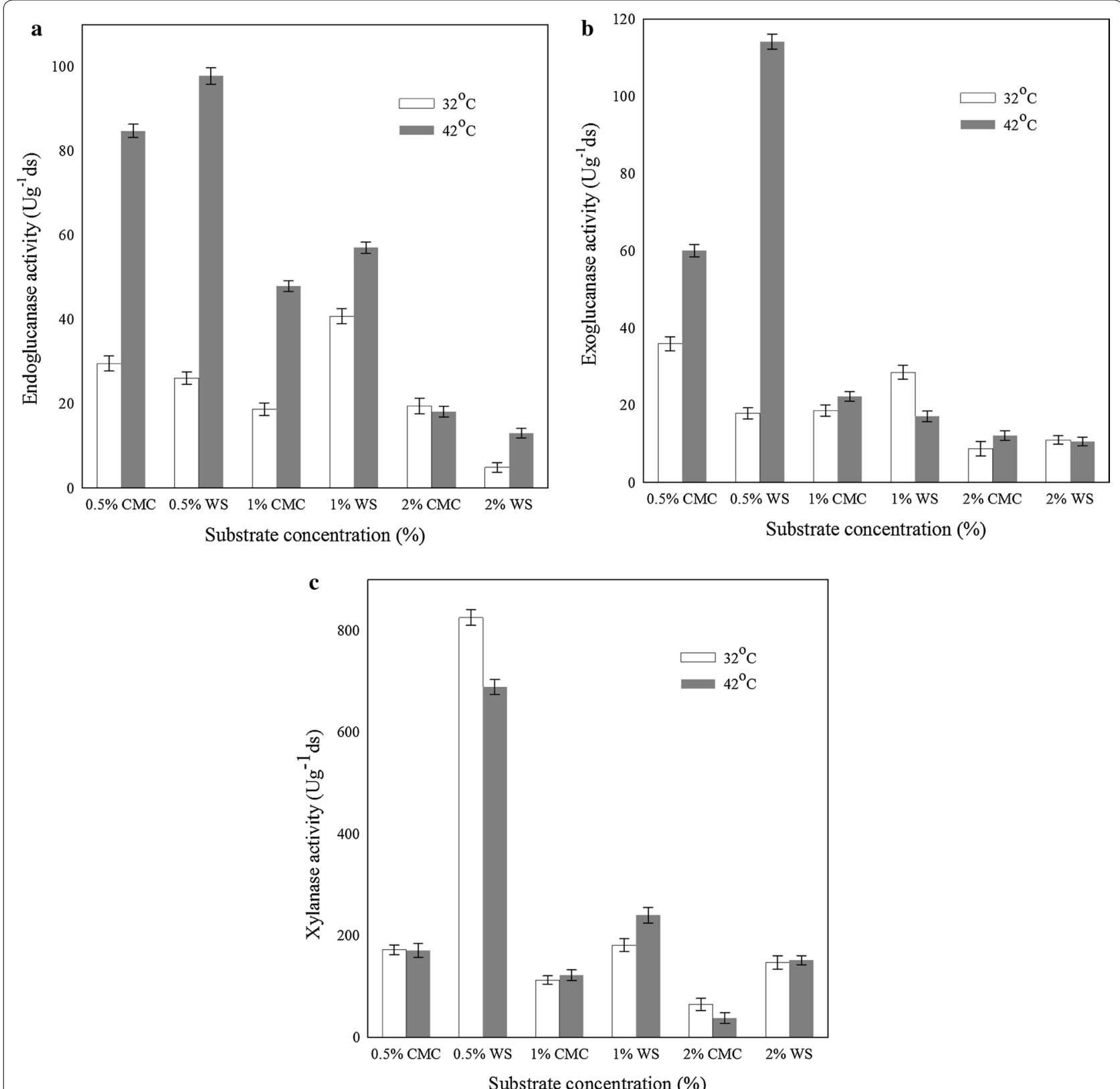

Fig. 2 Effect of different substrates (CMC and Wheat Straw-WS) concentrations ( $0.5,1$ and $2 \%$ ) on a endoglucanase activity, b exoglucanase activity and $\mathbf{c}$ xylanase activity at 32 and $42^{\circ} \mathrm{C}$. The error bar range represents standard deviation from mean, $t$-test significance level $p<0.005$ 
hydrolysate. The expression of xylanases with wheat straw could be attributed to the presence of xylan [30]; however, it was interesting to find xylanase production even in the presence of $\mathrm{CMC}$, which is apparently xylan free. Earlier reports related to xylanase production indicate that the strains of Aspergillus sp., Penicillium sp., etc. show very high xylanase activities ranging from 5000 to $7000 \mathrm{U} \mathrm{g}^{-1} \mathrm{ds}[31,32]$ along with cellulase production. It is expected that genetic improvements in the new yeast isolate may lead to increased expression of cellulolytic enzymes.

\section{Wheat straw hydrolysis}

Different acids have been used to carry out biomass pretreatments $[33,34]$ and the use of phosphoric acid is known to generate lesser inhibitory compounds in the hydrolysate [35]. The quantity of inhibitory compounds generated during biomass pretreatment is mainly dependant on pretreatment severity. An earlier study from the author's laboratory optimized wheat straw pretreatment using $0.2 \%$ phosphoric acid at $150{ }^{\circ} \mathrm{C}$ for $15 \mathrm{~min}$ [19] and the same conditions were used for biomass pretreatment in the present study. The cellulose, hemicellulose and lignin content of biomass before and after phosphoric acid pretreatment was determined (Table 1). Phosphoric acid pretreatment of wheat straw caused approx. $65 \%$ lignin removal and $64 \%$ hemicellulose hydrolysis. After separating the hydrolysate and neutralizing the biomass, the cellulosic biomass was subjected to hydrolysis with the enzymes produced by the new yeast at an approximate enzyme loading of $20 \mathrm{U} \mathrm{g}^{-1}$ of wheat straw for $48 \mathrm{~h}$ at $50{ }^{\circ} \mathrm{C}$. The sugar hydrolysate generated contained about $500 \mathrm{mg}$ glucose and $30 \mathrm{mg}$ xylose per gram of dry wheat straw used.

It is widely acknowledged that the cost of producing cellulosic ethanol can be lowered by optimizing conversion of the released pentoses and hexoses into ethanol or by converting pentoses into an additional high value compound such as xylitol [36]. On the basis of earlier reports related to ethanol and xylitol production by Candida species [20,36], investigations were carried out to determine ethanol and xylitol fermentation capacities of the new yeast isolate.

Table 1 Compositional analysis of wheat straw (before and after) treatment with $0.2 \%(\mathrm{v} / \mathrm{v})$ phosphoric acid at $150{ }^{\circ} \mathrm{C}$ for $15 \mathrm{~min}$

\begin{tabular}{lllr}
\hline & Cellulose (\%) & Hemicellulose (\%) & Lignin (\%) \\
\hline Before pretreatment & $39.65 \pm 2.1$ & $7.95 \pm 0.6$ & $15.19 \pm 1.2$ \\
After pretreatment & $48.68 \pm 1.8$ & $2.85 \pm 0.4$ & $5.28 \pm 0.8$ \\
\hline
\end{tabular}

\section{Pentose and hexose fermentation by Candida tropicalis} MTCC 25057 in synthetic media

Biomass consists of approx. 20-40\% of hemicellulose [37], which upon hydrolysis, releases xylose as the main component. The naturally occurring industrial ethanol producing yeast, Saccharomyces cerevisae, cannot utilize xylose and hence a hexose and pentose fermenting microorganism is needed. Candida sp. is a distinctive class of yeast that can ferment glucose into ethanol and xylose into xylitol and ethanol [20,36-38]. Over the years, studies have shown that different strains of Candida sp. produce optimum levels of xylitol (from xylose) and ethanol (from glucose and xylose) under aerobic and anaerobic conditions, respectively [20].

During the current investigations, it was observed that Candida cell growth and ethanol production patterns were similar under both, aerobic and anaerobic conditions (Fig. 3a, b). Ethanol production using Candida strains is essentially an anaerobic process. However, the new Candida isolate could produce comparable concentrations of ethanol under aerobic conditions although the productivities were decreased.

On culturing the yeast strain in synthetic YEPD media under anaerobic conditions, maximum ethanol levels of $\sim 36 \mathrm{~g} \mathrm{~L}^{-1}$ were obtained within $24 \mathrm{~h}$, whereas similar ethanol concentrations were attained under aerobic conditions after $48 \mathrm{~h}$ of incubation (Fig. 3a, b). Under anaerobic and aerobic conditions, the corresponding glucose consumption of 100 and $80 \%$ was observed within $24 \mathrm{~h}$. Under aerobic conditions, the complete consumption of the remaining $20 \%$ glucose required extended incubation for up to $48 \mathrm{~h}$ (Fig. 3a). Therefore, the ethanol yields $\left(0.36 \mathrm{~g} \mathrm{~g}^{-1}\right.$, i.e., $\sim 72 \%$ conversion) were similar while the ethanol productivities under anaerobic conditions $\left(1.5 \mathrm{~g} \mathrm{~L}^{-1} \mathrm{~h}^{-1}\right)$ were higher than under aerobic conditions $\left(0.75 \mathrm{~g} \mathrm{~L}^{-1} \mathrm{~h}^{-1}\right)$. Under both the conditions, approx. 3-4 $\mathrm{g} \mathrm{L}^{-1}$ glycerol was detected in the medium (data not shown).

The Candida tropicalis isolate could also utilize xylose under aerobic conditions and produce xylitol $\left(68 \pm 2 \mathrm{~g} \mathrm{~L}^{-1}\right)$ within $96 \mathrm{~h}$ of fermentation (Fig. 3c) when cultured in YEPD media. The xylitol yields and productivities obtained during aerobic fermentations were $0.67 \mathrm{~g} \mathrm{~g}^{-1}$ (67\% conversion) and $0.70 \mathrm{~g} \mathrm{~L}^{-1} \mathrm{~h}^{-1}$, respectively. No consumption of xylose was observed under anaerobic conditions even after extended incubation up to $120 \mathrm{~h}$ (data not shown). It has been previously reported that nicotinamide adenine dinucleotide phosphate (NADPH) is required for the functioning of xylose reductase, a key enzyme involved in xylitol production [39], which is regenerated only under aerobic 

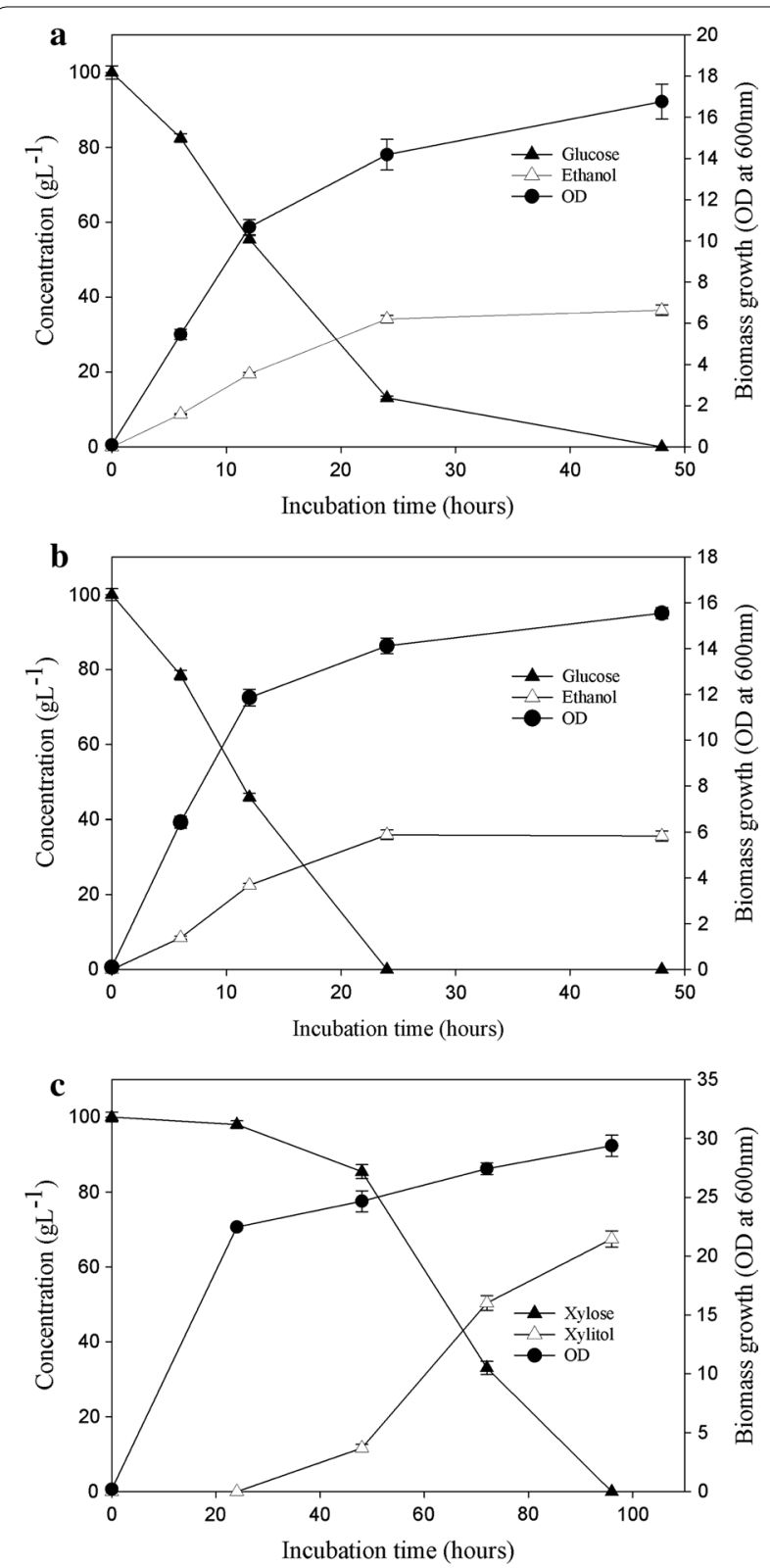

Fig. 3 Fermentation of glucose under aerobic $\mathbf{a}$, anaerobic $(\mathbf{b})$ and of xylose under aerobic $\mathbf{c}$ conditions by Candida tropicalis at $32^{\circ} \mathrm{C}$ in synthetic media. The error bar range represents standard deviation from mean, $t$-test significance level $p<0.005$

conditions [40] possibly preventing anaerobic utilization of xylose.

Since lignocellulosic hydrolysate contains a mixture of pentose and hexose sugars, it was necessary to determine the ability of the isolate to ferment both simultaneously. Therefore, in order to simulate fermentation of lignocellulosic hydrolysate containing mixed sugars (hexose and pentose), the strain of $C$. tropicalis was cultured in synthetic lab media in which $50 \mathrm{~g} \mathrm{~L}^{-1}$ each of xylose and glucose had been added. The anaerobic cultivation of C. tropicalis in glucose-xylose medium led to complete utilization of glucose within $24 \mathrm{~h}$ whereas xylose remained unutilized in the medium (Fig. 4a). The maximum ethanol concentrations obtained under anaerobic $\left(18.8 \pm 0.8 \mathrm{~g} \mathrm{~L}^{-1}\right)$ and aerobic $\left(20.4 \pm 1.3 \mathrm{~g} \mathrm{~L}^{-1}\right)$ conditions as well as the ethanol yields of 0.37 and 0.4 $\mathrm{g} \mathrm{g}^{-1}$ were found to be similar. However, no xylitol was detected during anaerobic fermentations of Candida tropicalis even till the end of the fermentation (Fig. 4a). Under aerobic cultivation, xylose utilization started $48 \mathrm{~h}$ after complete utilization of glucose (Fig. 4b) and a xylitol yield and productivity of $0.93 \mathrm{~g} \mathrm{~g}^{-1}$ and $0.28 \mathrm{~g} \mathrm{~L}^{-1} \mathrm{~h}^{-1}$, respectively, were obtained. The delayed onset of xylose utilization could be attributed either to the higher affinity of the xylose transporter for glucose or the repression of the first two genes of the xylose utilization pathway, viz. xylose reductase and xylitol dehydrogenase, as was previously reported for Candida shehatae and Pichia stipitis $[41,42]$. The xylitol yield obtained in case of mixed sugar fermentation in this study was higher than the previously
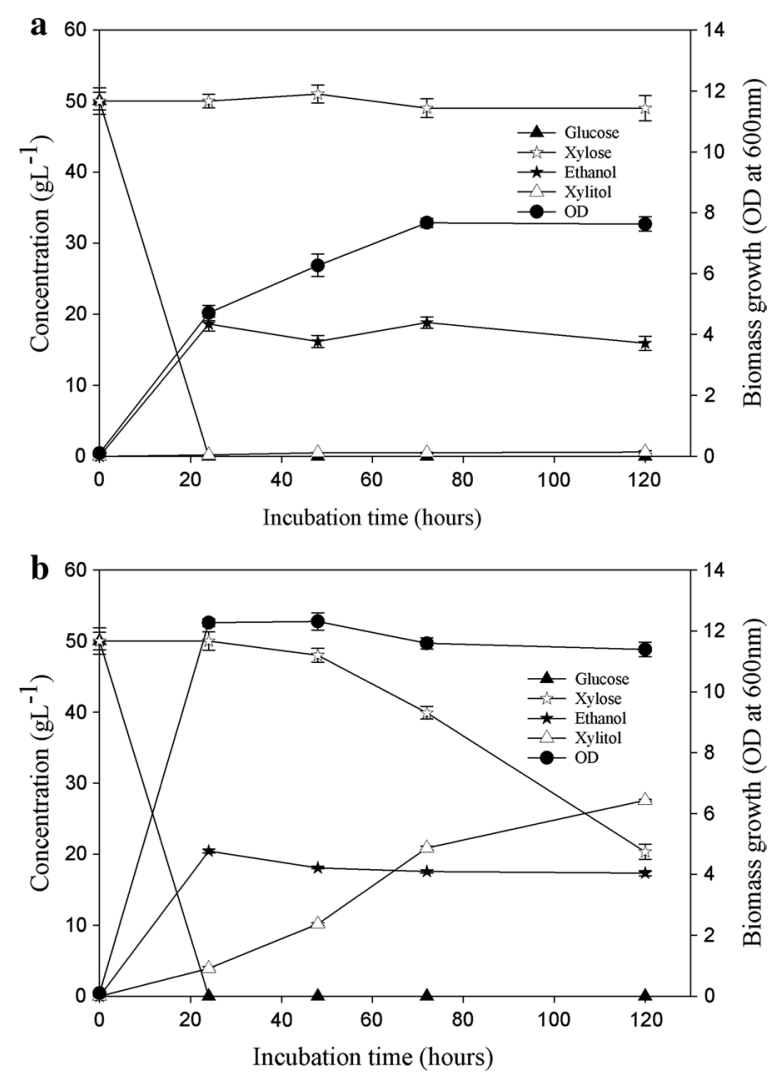

Fig. 4 Fermentation of synthetic media containing glucose and xylose under $\mathbf{a}$ anaerobic and $\mathbf{b}$ aerobic conditions to produce ethanol and xylitol by Candida tropicalis at $32^{\circ} \mathrm{C}$. The error bar range represents standard deviation from mean, $t$-test significance level $p<0.005$ 
reported values in the range of $0.49-0.84 \mathrm{~g} \mathrm{~g}^{-1}$ produced by other Candida strains [43, 44]. Another important observation made during the studies was that the yield of xylitol obtained when xylose was the sole carbon source was lower $\left(0.67 \mathrm{~g} \mathrm{~g}^{-1}\right)$ than the yield $\left(0.93 \mathrm{~g} \mathrm{~g}^{-1}\right)$ obtained on using xylose and glucose in the media. The increased xylitol yield in the presence of mixed sugars might have occurred due to the utilization of glucose for biomass formation resulting in xylose being consumed only for xylitol formation and not biomass, or the sufficient availability of NADPH (essential for the optimal activity of the xylose reductase enzyme) which is regenerated best in the presence of glucose [40].

\section{Pentose and Hexose fermentation by Candida tropicalis MTCC 25057 in hydrolysate}

Although wheat straw pretreatment with $0.2 \%$ phosphoric acid has been optimized in our laboratory due to minimal inhibitor generation, here we have used harsher pretreatment conditions ( $4 \%$ phosphoric acid) so as to achieve maximal xylose generation in the hydrolysate as this yeast isolate has the capability to withstand high inhibitor concentrations. Interestingly, even after the use of such highly acidic conditions for pretreatment, the amount of inhibitors produced was minimal $-1 \mathrm{~g} \mathrm{~L}^{-1}$ furfural and $0.075 \mathrm{~g} \mathrm{~L}^{-1} \mathrm{HMF}$, reaffirming the use of phosphoric acid as an effective yet gentle pretreatment agent. The pretreated hydrolysate generated was fermented initially using the new yeast isolate after supplementation with minimal salts only. However, no ethanol or xylitol production was observed (data not shown). Subsequently, to meet the nutritional deficiencies, an additional nitrogen source ( $1 \%$ yeast extract) was added to the hydrolysate which resulted in increased xylose utilization. Almost $60 \%$ of the xylose was consumed within the first twelve hours of fermentation itself and no residual xylose was observed beyond $72 \mathrm{~h}$ of fermentation (Fig. 5a). Xylitol production reached maximum levels of $\sim 15 \pm 1 \mathrm{~g} \mathrm{~L}^{-1}$ in $72 \mathrm{~h}$ with an average yield of $\sim 32 \%$. The hydrolysate also contained some amount of glucose $\left(10 \mathrm{~g} \mathrm{~L}^{-1}\right)$ which was converted into ethanol $\left(\sim 4.5 \mathrm{~g} \mathrm{~L}^{-1}\right)$ in the initial $24 \mathrm{~h}$.

In a similar study reported earlier, fermentation of concentrated corn cob hydrolysate (without nutritional supplementation) using a hydrolysate adapted Candida strain resulted in a xylitol yield of approx. $14.81 \%$ with most of the xylose being diverted for biomass formation which affected the final yields [45]. In our study, a xylitol yield of $\sim 32 \%$ was achieved using a wild-type Candida isolate; although here too, most of the sugar was being used for cell growth instead of xylitol production. Further improvements in xylitol titers and yields may be achieved by strain adaptation, optimization of the cultivation
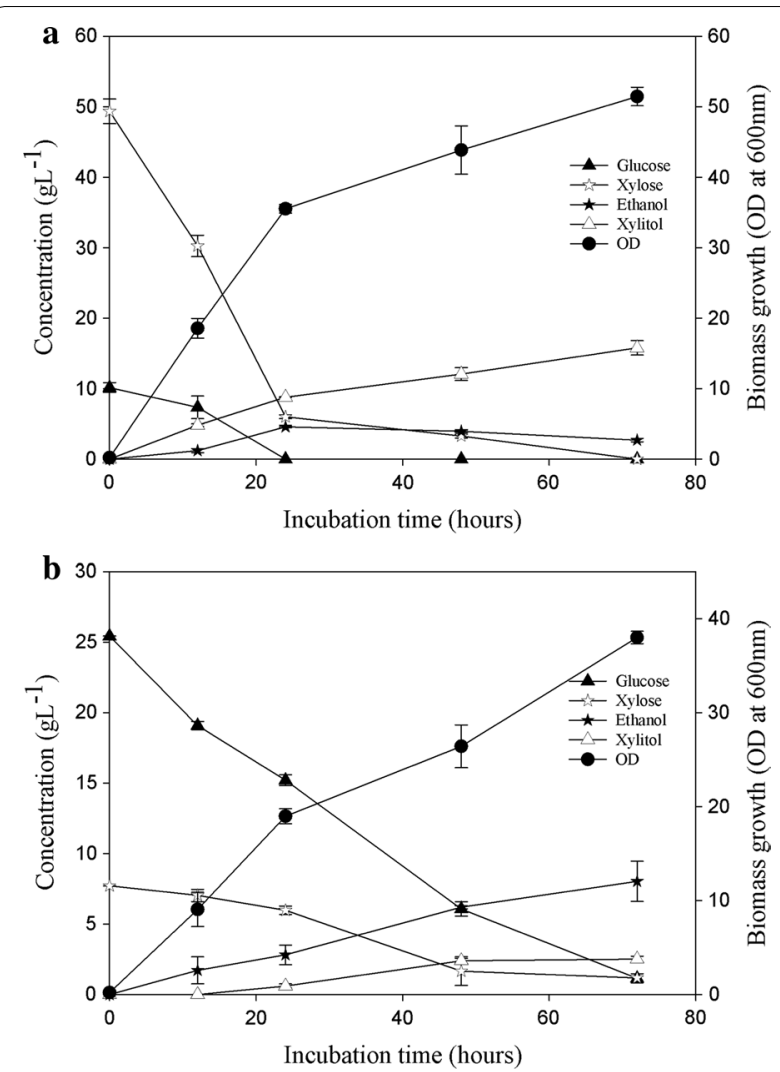

Fig. 5 Fermentation of pretreated hydrolysate under anaerobic $\mathbf{a}$ and aerobic $\mathbf{b}$ conditions to produce ethanol and xylitol by Candida tropicalis at $32{ }^{\circ} \mathrm{C}$. The error bar range represents standard deviation from mean, $t$-test significance level $p<0.005$

conditions, enriching the lignocellulosic hydrolysate for better cell growth, etc.

The sugar hydrolysate obtained post-enzymatic saccharification of the pretreated wheat straw was also fermented using the same yeast strain. This hydrolysate has more hexoses than pentoses as it is derived from the cellulose rich biomass. In this case also, supplementation of the hydrolysate with additional $\mathrm{N}$ source led to greater diversion of the sugars to cell growth than to product formation. The yeast was able to convert $\sim 25 \mathrm{~g} \mathrm{~L}^{-1}$ glucose to $7.3 \pm 1.1 \mathrm{~g} \mathrm{~L}^{-1}$ ethanol with a net yield of $0.28 \mathrm{~g} \mathrm{~g}^{-1}$ (Fig. 5b), which was slightly lower than the ethanol yield observed in case of mixed sugar fermentation in synthetic medium. The sugar hydrolysate also contained $\sim 7.5 \mathrm{~g} \mathrm{~L}^{-1}$ of xylose that was converted to xylitol in $24 \mathrm{~h}$ with a yield of $0.31 \mathrm{~g} \mathrm{~g}^{-1}$. The ethanol yield and productivity could be enhanced further by fine tuning the addition of nutritional supplements so as to ensure maximum sugar fermentation into ethanol production. A recently published review by Jouzani and Taherzadeh [46] comprehensively covers almost all the wild-type single microbial strains, microbial co-cultures as well as genetically engineered 
microorganisms with cellulolytic activities and ethanol producing abilities that showed potential for converting biomass into bioethanol via CBP. In comparison, the strain isolated in the present study also showed cellulolytic as well as ethanol fermenting abilities. In addition, the yeast strain also exhibited significant inhibitor tolerance and produced xylitol from hemicellulosic sugars. To establish the strain's potential for CBP applications, detailed investigations into the metabolic pathways are needed.

Generally, ethanol producing yeast such as Saccharomyces, Kluyveromyces naturally lack cellulase expression and hence cellulolytic fungi such as Trichoderma and Aspergillus are used for producing cellulolytic enzymes. However, yeast cells are widely preferred as the hosts for recombinant enzyme production due to their robust nature, rapid growth rates and higher protein secretion [47-49]. In view of the advantages offered by yeast cells, research efforts have focussed on imparting cellulolytic abilities for their development as CBP-suitable hosts [50-52]. To develop cellulolytic yeast, multiple genes coding for various cellulases have to be cloned and their gene products need to be expressed in a stable manner, at a certain proportion and in higher quantities for achieving hydrolytic action on cellulose in a synergistic manner. The insertion of $\delta$-retrotransposons regulates simultaneous expression of multiple genes $[53,54]$, whereas the synthetic promoter and terminator sequences improve the stability as well as activity of the mRNA $[55,56]$ while hybrid transcriptional activators enhance the secretion of cellulolytic enzymes [57]. Earlier studies have also focussed on increasing the extracellular enzyme secretion by manipulating the expression of proteins such as SNAREs, karyopherins and superoxide dismutase, which have been implicated in the regulation of intracellular membrane transport $[58,59]$. However, all these approaches in yeast engineering have met with limited success since the cellulolytic enzyme yields were much lower than those produced by the established strains such as Aspergillus, Trichoderma etc. [60-62].

An ideal CBP operation for lignocellulosic bioethanol production would depend upon higher expression of hydrolytic enzymes for optimum biomass hydrolysis and the rapid fermentation of released sugars, all occurring within a relatively narrow range of process parameters. In actuality, since the temperature optima for enzyme production $\left(30-32{ }^{\circ} \mathrm{C}\right)$, biomass hydrolysis $\left(50{ }^{\circ} \mathrm{C}\right)$ and fermentation $\left(30-32{ }^{\circ} \mathrm{C}\right)$ vary, the processes are still carried out in a successive manner. During our studies, the inhibitor tolerant strain of Candida exhibited maximal enzyme production $\left(42{ }^{\circ} \mathrm{C}\right.$ and $\left.\mathrm{pH} 6-7\right)$ and biomass hydrolysis (at $50{ }^{\circ} \mathrm{C}$ and $\mathrm{pH}$ 5) within a relatively narrower range of process parameters, thereby indicating its potential for CBP applications.

Further improvements in the new yeast isolate can include overexpressing native cellulases by inserting multiple gene copies and the development of recombinants by inserting genes from conventional enzyme producers such as Aspergillus or Trichoderma. The thermostability, substrate specificity, etc. of native cellulases produced by $C$. tropicalis isolate can also be improved via protein engineering. Ongoing investigations in the authors' laboratory also focus upon adaptation of the yeast to nutritionally deficient environments such as hydrolysate as well as imparting the ability to co-utilize hexose and pentose sugars for increased productivity during mixed sugar fermentations.

\section{Conclusions}

Till now, several wild-type bacteria and filamentous fungi along with their recombinant strains and a few genetically engineered yeast were considered as potential CBP candidates for lignocellulosic ethanol production. The current work is the first definitive report describing a new strain of Candida tropicalis with ability to produce cellulolytic enzymes, ethanol and xylitol, thereby making it a prospective candidate for consolidated bioprocessing. The new yeast isolate also exhibited high tolerance to inhibitors such as furfural, HMF and acetic acid, found commonly in lignocellulosic hydrolysate. In addition, it produced cellulases and xylanases over a wide range of temperatures and in the presence of diverse cellulosic substrates. However, in order to carry out efficient hydrolysis of pre-treated biomass, the expression and activities of the cellulolytic enzymes will have to be significantly improved by the over-expression of heterologous cellulases and accessory proteins. Also, the ethanol and xylitol titers obtained during fermentations in hydrolysates were relatively lower despite the strain's tolerance to inhibitors and this could be attributed to the existing nutritional deficiencies in hydrolysates. The fermentative performance of the new yeast strain and the co-utilization of mixed sugars can be further improved by strain adaptation to nutritionally deficient conditions and genetic engineering.

\section{Methods}

\section{Microorganism and culture conditions}

Soil samples were collected from Sri Chamarajendra Zoological Gardens, Mysore, India and stored in sterile containers at $4{ }^{\circ} \mathrm{C}$ until subsequent use. Approximately, $1 \mathrm{~g}$ of soil sample was inoculated into yeast extract peptone dextrose broth (YEPD) and incubated at $32{ }^{\circ} \mathrm{C}$ for 
$48 \mathrm{~h}$. On obtaining growth, the liquid culture was serially diluted in sterile saline and plated onto agar plates with $1 \% \mathrm{CMC}$ which were incubated at $32{ }^{\circ} \mathrm{C}$ for $48 \mathrm{~h}$. The colonies obtained were sub-cultured till pure isolates were obtained. Upon microscopic observations, one of the isolated colonies was found to be a yeast. The isolate was maintained on YEPD agar slants at $4{ }^{\circ} \mathrm{C}$. Liquid cultures of the isolate were obtained by inoculating a loopful of culture from YEPD slants into YEPD broth and incubating at $32{ }^{\circ} \mathrm{C}$ for $24 \mathrm{~h}$ at $150 \mathrm{rpm}$.

\section{Identification of new strain}

Strain identification of the new yeast isolate was done by sequencing the $18 \mathrm{~S}, 5.8 \mathrm{~S}$ and $26 \mathrm{~S}$ rRNA and the isolate was found to be $C$. tropicalis. The primers used for strain identification spanned the $18 \mathrm{~S}$ rRNA, the variable D1-D2 domain of the 26S rRNA and the internal transcribed spacer region of the $5.8 \mathrm{~S}$ rRNA. The primer sequences were as follows: 18S fwd 5'-TCCTCCGCTTATTGATATGC-3', 18S_rev $5^{\prime}$-GAAGTAAAAGTCGTAACAAGG-3 ${ }^{\prime}, 26 \mathrm{~S} \_$fwd 5'GCATATCAATAAGCGGAGGAAAAAG-3', 26S_rev 5'-GGTCCGTGTTTCAAGACG-3', ITS1 5'TCCGTAGG TGAACCTGCGG- $3^{\prime}$ and ITS4 $5^{\prime}$-TCCTCCGCTTATTG ATATGC- $3^{\prime}$. The PCR conditions used were: initial denaturation at $95^{\circ} \mathrm{C}$ for $5 \mathrm{~min}$, followed by 30 cycles of denaturation, annealing and extension at 95,52 and $72{ }^{\circ} \mathrm{C}$, respectively, for $30 \mathrm{~s}$ or $1 \mathrm{~min}$. A final product extension at $72{ }^{\circ} \mathrm{C}$ for ten minutes was also done before analysing the PCR products by gel electrophoresis. The PCR products were purified using the GeneJET gel extraction kit (Thermo Fisher Scientific) before sequencing. The strain was submitted to Microbial Type Culture Collection (MTCC), India and assigned the accession number -MTCC 25057.

\section{Biomass pretreatment and enzymatic hydrolysis}

Wheat straw procured from local sources around Bangalore was stored and used throughout the study. Wheat straw was subjected to phosphoric acid $(0.2 \% \mathrm{v} / \mathrm{v})$ pretreatment as described previously [63]. The cellulose, hemicellulose and lignin composition of the wheat straw was determined using standard NREL procedures [64]. The liquid hydrolysate obtained was neutralized to $\mathrm{pH}$ 6-7 using ammonia and used for cellulolytic enzyme production. The solid biomass obtained after phosphoric acid pretreatment was washed with distilled water, dried at $60{ }^{\circ} \mathrm{C}$ and used for enzymatic hydrolysis. Briefly, $5 \mathrm{~g}$ of pretreated biomass, $20 \mathrm{U} \mathrm{g}^{-1} \mathrm{ds}$ enzyme and $50 \mathrm{~mL}$ sodium citrate buffer $(50 \mathrm{mM}, \mathrm{pH}$ 4.8) were taken in $250 \mathrm{~mL}$ Erlenmeyer flasks and incubated at $50{ }^{\circ} \mathrm{C}$ and $150 \mathrm{rpm}$ shaking for $24-48 \mathrm{~h}$. The sugar hydrolysate was separated by centrifugation at $15,000 \mathrm{rpm}$ for $10 \mathrm{~min}$ and the reducing sugar content was determined by uHPLC.

\section{Cellulase and xylanase production under submerged fermentation}

Submerged fermentation was carried out by inoculating $0.2 \mathrm{~mL}$ of the exponential phase MTCC 25057 culture to $250 \mathrm{~mL}$ Erlenmeyer flasks containing $20 \mathrm{~mL}$ of wheat straw hydrolysate supplemented with minimal salts. The composition of minimal salts $\left(\mathrm{g} \mathrm{L}^{-1}\right)$ was $-\mathrm{NaNO}_{3}: 2.5$, $\mathrm{KH}_{2} \mathrm{PO}_{4}: 1, \mathrm{MgSO}_{4} \cdot 7 \mathrm{H}_{2} \mathrm{O}: 0.5, \mathrm{KCl}: 0.5$. To these flasks, cellulosic substrates (CMC or pretreated WS) at different concentrations $(0.5 \% \mathrm{w} / \mathrm{v}, 1 \% \mathrm{w} / \mathrm{v}$ and $2 \% \mathrm{w} / \mathrm{v})$ were added. The cultures were incubated on a rotary shaker $(150 \mathrm{rpm})$ at different temperatures $\left(32\right.$ and $\left.42{ }^{\circ} \mathrm{C}\right)$ and for varying periods $(24,48,72$ and $96 \mathrm{~h})$. The crude supernatant obtained by centrifuging the culture broth at $8000 \mathrm{rpm}$ for $10 \mathrm{~min}$ was used for determining enzyme activity.

\section{Enzyme assays}

Crude endoglucanase activity was determined by the CMC method [65]. The substrate was prepared by solubilizing carboxymethyl cellulose (Sigma) $(2 \% \mathrm{w} / \mathrm{v})$ in $0.05 \mathrm{M}$ sodium citrate buffer at $\mathrm{pH} 4.8$. Briefly, $0.5 \mathrm{~mL}$ of the crude enzyme supernatant (diluted appropriately) was added to $0.5 \mathrm{~mL}$ of the substrate and incubated at $50{ }^{\circ} \mathrm{C}$ for $30 \mathrm{~min}$. The reducing sugars liberated were estimated by the DNS method [66]. Crude exoglucanase activity was determined by the filter paper assay method [67]. The substrate used was $50 \mathrm{mg}$ of Whatman No. 1 filter paper in $0.05 \mathrm{M}$ sodium citrate buffer at $\mathrm{pH} 4.8$. The crude enzyme supernatant $(0.5 \mathrm{~mL})$ was added to $1 \mathrm{~mL}$ of the buffer having $50 \mathrm{mg}$ filter paper and incubated at $50{ }^{\circ} \mathrm{C}$ for $60 \mathrm{~min}$ and the reducing sugars liberated were estimated by the DNS method. Xylanase activity was determined by the beechwood xylan assay method [65]. Substrate preparation was done by adding beechwood xylan (Sigma) (1 \% w/v) to $0.05 \mathrm{M}$ sodium citrate buffer, $\mathrm{pH}$ 4.8. The appropriately diluted crude enzyme supernatant $(0.1 \mathrm{~mL})$ was added to $0.5 \mathrm{~mL}$ of the substrate and $0.4 \mathrm{~mL}$ of buffer and incubated at $50{ }^{\circ} \mathrm{C}$ for $15 \mathrm{~min}$. The reducing sugars released were measured by the DNS method. All the estimations were carried out in triplicates. The enzyme activity was expressed in terms of International units (IU) for endoglucanase and xylanase and filter paper unit (FPU) for exoglucanase, respectively, or as units per gram of dry substrate (gds), i.e., $\mathrm{U} \mathrm{g}^{-1}$ ds. One IU or FPU is defined as the amount of enzyme activity required to release one micromole of reducing sugar from a cellulosic substrate (CMC, xylan, 
filter paper, etc.) per $\mathrm{mL}$ in a minute under the suitable assay conditions.

\section{Fermentation conditions}

The C. tropicalis MTCC 25057 strain was grown in $50 \mathrm{~mL}$ of yeast extract-peptone broth $\left(20 \mathrm{~g} \mathrm{~L}^{-1}\right.$ peptone and $10 \mathrm{~g} \mathrm{~L}^{-1}$ yeast extract) supplemented with either $10 \%$ glucose, $10 \%$ xylose or a mixture of $5 \%$ glucose and $5 \%$ xylose in $250 \mathrm{~mL}$ Erlenmeyer flasks in an incubator shaker maintained at $32{ }^{\circ} \mathrm{C}$ and $150 \mathrm{rpm}$. Samples were collected at appropriate intervals and the metabolites produced were analysed using UHPLC. Anaerobic condition was maintained by flushing nitrogen initially through the headspace of the flask and then incubating at $32{ }^{\circ} \mathrm{C}$ as mentioned previously. For inhibitor tolerance studies, furfural, 5-hydroxymethylfurfural or acetic acid (Himedia Laboratories) was added to the yeast extract-peptone broth with $1.5 \%$ xylose and $0.5 \%$ glucose (to simulate pretreated hydrolysate), in concentrations ranging from 0.5 to $3 \mathrm{~g} \mathrm{~L}^{-1}$ and grown at $32{ }^{\circ} \mathrm{C}$ for $24 \mathrm{~h}$. The yeast was grown in YEPD, i.e., yeast extract peptone broth with 20 $\mathrm{g} \mathrm{L}^{-1}$ glucose medium maintained at different $\mathrm{pH}(4,5,6$, $7,8,9,10)$ and at different temperatures $(32,37,42,45$, $50{ }^{\circ} \mathrm{C}$ ) for $24 \mathrm{~h}$ for determining the $\mathrm{pH}$ and temperature tolerance of the strain.

The pretreated and sugar hydrolysates were supplemented either with minimal salts (as mentioned previously) or with $10 \mathrm{~g} \mathrm{~L}^{-1}$ yeast extract for ethanol/xylitol production studies. The yeast was inoculated from a fresh plate into $50 \mathrm{~mL}$ hydrolysate and incubated at $150 \mathrm{rpm}$ at $32{ }^{\circ} \mathrm{C}$ in $250 \mathrm{~mL}$ Erlenmeyer flasks. The samples were collected at suitable intervals and analysed.

\section{Analytical methods}

The soluble sugars or metabolites content in the culture samples were determined using a 1290 Infinity series UHPLC system (Agilent) equipped with a Hiplex $\mathrm{H}$ anion exchange column (Agilent). Filtered and degassed $5 \mathrm{mM} \mathrm{H}_{2} \mathrm{SO}_{4}$ was used as the mobile phase at a flow rate of $0.6 \mathrm{~mL} / \mathrm{min}$. The column was maintained at $45{ }^{\circ} \mathrm{C}$ in a thermostat chamber, while the refractive index (RI) detector was maintained at $55{ }^{\circ} \mathrm{C}$. The concentrations of glucose, xylose, ethanol and xylitol were estimated using appropriate calibration curves. The biomass or cell density of the culture samples was estimated by measuring the optical density at $600 \mathrm{~nm}$ using a Perkin Elmer Lambda $35 \mathrm{UV} /$ visible spectrophotometer.

\footnotetext{
Abbreviations

MTCC: microbial type culture collection; CBP: consolidated bioprocessing; HMF: hydroxymethylfurfural; CMC: carboxymethylcellulose; WS: wheat straw; YEPD: yeast extract peptone dextrose; NADPH: nicotinamide adenine dinucleotide phosphate; N: nitrogen; SNAREs: soluble NSF Attachment Protein Receptor; PCR: polymerase chain reaction; NREL: National Renewable Energy
}

Laboratory; DNS: dinitrosalicylic acid; UHPLC: ultra high pressure liquid chromatography; RI: refractive index.

\section{Authors' contributions}

AJM carried out the inhibitor tolerance, enzyme production and fermentation studies; AK performed the strain isolation and characterization; NMS participated in the pretreatment and hydrolysis of biomass; PVC and NC provided technical inputs; HRV designed the study and analysed the data. All authors contributed to writing and revising the manuscript. All authors read and approved the final manuscript.

\section{Acknowledgements \\ The authors thank Hindustan Petroleum Corporation Limited's (HPCL) HP-Green Research and Development Centre (HPGRDC), Bangalore for the financial support to carry out this research work.}

\section{Competing interests}

The authors declare that they have no competing interests.

\section{Availability of supporting data}

All the data have been provided in the main manuscript.

\section{Consent for publication}

Consent was obtained from all the authors of the manuscript for the publication.

Received: 6 April 2016 Accepted: 14 July 2016

Published online: 26 July 2016

\section{References}

1. Limayem A, Ricke SC. Lignocellulosic biomass for bioethanol production: current perspectives, potential issues and future prospects. Prog Energ Combust. 2012;38:449-67.

2. Saha BC, Nichols NN, Qureshi N, Kennedy GJ, Iten LB, Cotta MA. Pilot scale conversion of wheat straw to ethanol via simultaneous saccharification and fermentation. Bioresour Technol. 2015;175:17-22.

3. Adsul MG, Jain MS, Gaikaiwari SA, Gokhale D. Development of biocatalysts for production of commodity chemicals from lignocellulosic biomass. Bioresour Technol. 2011;102:4304-12.

4. PeraltaYahya PP, Zhang F, Cardayre SB, Keasling JD. Microbial engineering for the production of advanced biofuels. Nature. 2012;488:320-8.

5. Jonsson LJ, Alrikkson B, Nilvebrant N. Bioconversion of lignocellulose: inhibitors and detoxification. Biotechnol Biofuel. 2013:6:16.

6. Menon V, Rao M. Trends in bioconversion of lignocellulose: biofuels, platform chemicals \& biorefinery concept. Prog Energ Combust. 2012;38:522-50.

7. Ghosh D, Dasgupta D, Agrawal D, Kaul S, Adhikari DK, Kurmi AK. Fuels and chemicals from lignocellulosic biomass: an integrated biorefinery approach. Energ Fuel. 2015;29:3149-57.

8. Bannerjee S, Mudaliar S, Sen R. Giri Salupte D, Chakrabarti T: Commercializing lignocellulosic ethanol: technology bottlenecks and possible remedies. Biofuels Bioprod Bioref. 2010;4:77-93.

9. Galbe M, Zacchi G. A review of the production of ethanol from softwood. Appl Microbiol Biotechnol. 2002;59:618-28.

10. Verduyn C, van Kleef R, Frank J, Schreuder H, van Dijken JP, Scheffers WA. Properties of the NAD(P)H-dependent xylose reductase from the xylosefermenting yeast Pichia stipitis. Biochem J. 1985;226:669-77.

11. Ho NW, Lin FP, Huang S, Andrews PC, Tsao GT. Purification, characterization, and amino terminal sequence of xylose reductase from Candida shehatae. Enzyme Microb Technol. 1990;12:33-9.

12. Lee JK, Bong-Seong K, Sang-Yong K. Cloning and characterization of xy/1 gene, encoding an NADH-peferring xylose reductase from Candida parapsilosis, and its functional expression in Candida tropicalis. Appl Environ Microbiol. 2003;69:6179-88.

13. Albuquerque TL, Silva IJ, Macedo GR, Rocha MVP. Biotechnological production of xylitol from lignocellulosic wastes - a review. Proc Biochem. 2014:49:1779-89. 
14. Juwaied AA, Al-amiery AAH, Abdumuniem Anaam U. Optimization of cellulase production by Aspergillus niger and Tricoderma viride using sugar cane waste. J Yeast Fung Res. 2011;2:19-23.

15. Groenewald M, Robert V, Smith M. The value of the D1/D2 and internal transcribed spacers (ITS) domains for the identification of the yeast species belonging to the yeast genus Yamadazyma. Persoonia. 2011;26:40-6

16. Phylogenetic analysis of isolated biofuel yeasts based on. 5.8S rDNA and D1/D2 26S rDNA sequences. J Genet Eng Biotechnol. 2014;12:37-43.

17. Sulman S, Rehman A. Isolation and characterization of cellulose degrading Candida tropicalis W2 from environmental samples. Pak J Zool. 2013;45:809-16.

18. Almeida JR, Bertilsson M, Gorwa-Grauslund MF, Gorsich S, Liden G. Metabolic effects of furaldehydes and impacts on biotechnological processes. Appl Microbiol Biotechnol. 2009;82:625-38.

19. Kuila A, Rao PVC, Choudary NV, Gandham S, Velankar HR. Novel natural supplement for the production of fungal cellulases and application for enzymatic saccharification of wheat straw. Environ Prog Sus Energ. 2015:34:1243-8.

20. Cheng KK, Wu J, Lin ZN, Zhang JA. Aerobic and sequential anaerobic fermentation to produce xylitol and ethanol using non-detoxified acid pretreated corncob. Biotechnol Biofuel. 2014;7:166.

21. Zhao XQ, Bai FW. Mechanisms of yeast stress tolerance and its manipulation for efficient fuel ethanol production. J Biotechnol. 2009;144:23-30.

22. Arino J. Integrative responses to high $\mathrm{pH}$ stress in Saccharomyces cerevisiae. OMICS J Integr Biol. 2010;14:517-23.

23. Daquinag A, Fadri M, Jung SY, Qin J, Kunz J. The yeast PH domain proteins SIm1 and SIm2 are targets of sphingolipid signalling during the response to heat stress. Mol Cell Biol. 2007;27:633-50.

24. Tanskul S, Amornthatree K, Jaturonlak N. A new cellulase producing bacterium, Rhodococcus sp. MI 2: screening and optimization of culture conditions. Carbohyd Polym. 2013;92:421-8.

25. Berger E, Zhang D, Zverlov W, Schwarz WH. Two noncellulosomal cellulases of Clostridium thermocellum, Cel9I and Cel48Y, hydrolyse crystalline cellulose synergistically. FEMS Microbiol Lett. 2007;268:194-201.

26. Lambertz C, Garvey M, Klinger J, Heesel D, Klose H, Fischer R, Commandeur U. Challenges and advances in the heterologous expression of cellulolytic enzymes: a review. Biotechnol Biofuel. 2014;7:135.

27. Sohail M, Siddiqui R, Ahmad A, Khan SA. Cellulase production from Aspergillus niger MS82: effect of temperature and $\mathrm{pH}$. New Biotechnol. 2009:6:437-41.

28. Castro AM, Pedro KCNR, Cruz JC, Ferreira MC, Leite SGF, Pereira N Jr. Trichoderma harzianum IOC-4038: a promising strain for the production of a cellulolytic complex with significant $\beta$-glucosidase activity from sugarcane bagasse cellulignin. Appl Biochem Biotechnol. 2010;162:2111-22.

29. Lee DK, Owens VN, Boe A, Jeranyama P. Composition of herbaceous biomass feedstocks-North Central Centre. Brookings: South Dakota State University; 2007.

30. Park YS, Kang SW, Lee JS, Hong SI, Kim SW. Xylanase production in solid state fermentation by Aspergillus niger mutant using statistical experimental designs. Appl Microbiol Biotechnol. 2002;58:761-6.

31. Bakri Y, Jacques P, Thonart P. Xylanase production by Penicillium canescens 10-10 in solid-state fermentation. Appl Biochem Biotechnol. 2003;105-108:737-47

32. Adsul M, Sharma B, Singhania RR, Saini JK, Sharma A, Mathur A, Gupta $R$, Tuli DK. Blending of cellulolytic enzyme preparations from different fungal sources for improved cellulose hydrolysis by increasing synergism. RSC Adv. 2014:4:44716-32.

33. Kim KH, Tucker M, Nguyen Q. Conversion of bark-rich biomass mixture into fermentable sugar by two-stage dilute acid-catalyzed hydrolysis. Bioresour Technol. 2005;96:1249-55.

34. Sun Y, Cheng J. Hydrolysis of lignocellulosic materials for ethanol production: a review. Bioresour Technol. 2002;83:1-11.

35. Vasconselos SM, Santos AMP, Rocha GJM, Souto-Moier AM. Diluted phosphoric acid pretreatment of fermentable sugars in a sugarcane based biorefinery. Bioresour Technol. 2013;135:46-52.

36. Qu YB, Zhu MT, Liu K, Bao XM, Lin JQ. Studies on cellulosic ethanol production for sustainable supply of liquid fuel in China. Biotechnol J. 2006:1:1235-40.

37. Bruinenberg PM, Dijken JP, Scheffers WA. An enzymatic analysis of NADPH production and consumption in Candida ittilis. J Gen Microbiol. 1983;129:965-71.
38. Yokoyama S, Suzuki T, Kawai K, Horitsu H, Takamizawa K. Purification, characterization and structure analysis of NADPH-dependent D-xylose reductases from Candida tropicalis. J Ferment Bioeng. 1995;79:217-23.

39. Sauer U, Canonaco F, Heri S, Perrenoud A, Fischer E. The soluble and membrane-bound transhydrogenases UdhA and PntAB have divergent functions in NADPH metabolism of Escherichia coli. J Biol Chem. 2004:279:6613-9.

40. Webb SR, Lee H. Regulation of D-xylose utilization by hexoses in pentosefermenting yeasts. Biotechnol Adv. 1990;8:685-97.

41. Agbogbo FK, Coward-Kelly G, Torry-Smith M, Wenger KS. Fermentation of glucose/xylose mixtures using Pichia stipitis. Process Biochem. 2006;41:2333-6.

42. García FJ, Sánchez S, Bravo V, Cuevas M, Rigal L, Gaset A. Xylitol production from olive-pruning debris by sulphuric acid hydrolysis and fermentation with Candida tropicalis. Holzforschung. 2011;65:59-65.

43. Miura M, Watanabe I, Shimotori Y, Aoyama M, Kojima Y, Kato Y. Microbial conversion of bamboo hemicellulose hydrolysate to xylitol. Wood Sci Technol. 2013;47:515-22.

44. Ping $Y$, Ling HZ, Song G, Ge JP. Xylitol production from non-detoxified corncob hemicellulose acid hydrolysate by Candida tropicalis. Biochem Eng J. 2013;75:86-91.

45. Li Z, Guo X, Feng X, Li C. An environment friendly and efficient process for xylitol bioconversion from enzymatic corn cob hydrolysate by adapted Candida tropicalis. Chem Eng J. 2015;263:249-56.

46. Jouzani GS, Taherzadeh MJ. Advances in consolidated bioprocessing systems for bioethanol and butanol production from biomass: a comprehensive review. Biofuel Res J. 2015;5:152-95.

47. Young CL, Robinson AS. Protein folding and secretion: mechanistic insights advancing recombinant protein production in S. cerevisiae. Curr Opin Biotechnol. 2014;30:168-77.

48. Varnai A, Tang C, Bengtsson O, Atterton A, Mathiesen G, Eijsink VG. Expression of endoglucanases in Pichia pastoris under control of the GAP promoter. Microb Cell Fact. 2014;13:57.

49. Bommarius AS, Sohn M, Kang Y, Lee JH, Realff MJ. Protein engineering of cellulases. Curr Opin Biotechnol. 2014;29:139-45.

50. Haan RD, Mcbride JE, la Grange DC, Lynd LR, van Zyl JM. Functional expression of cellobiohydrolases in Saccharomyces cerevisiae. Enzyme Microb Technol. 2007:40:1291-9.

51. Chang JJ, Ho FJ, Ho CY, Wu YC, Hou YH, Huang CC, Shih MC, Li WH. Assembling a cellulase cocktail and a cellodextrin transporter into a yeast host for CBP ethanol production. Biotechnol Biofuels. 2013;6:19.

52. Apiwatanapiwat W, Murata Y, Kosugi A, Yamada R, Kondo A, Arai T, Rugthaworn P, Mori Y. Direct ethanol production from cassava pulp using a surface-engineered yeast strain co-displaying two amylases, two cellulases, and beta-glucosidase. Appl Microbiol Biotechnol. 2011;90:377-84.

53. Sakai A, Shimizu Y, Hishinuma F. Integration of heterologous genes into the chromosome of Saccharomyces cerevisiae using a delta sequence of yeast retrotransposon Ty. Appl Microbiol Biotechnol. 1990;33:302-6.

54. Liu L, Liu C, Zou S, Yang H, Hong J, Ma Y, Zhang M. Expression of cellulase genes in Saccharomyces cerevisiae via delta-integration subject to auxotrophic markers. Biotechnol Lett. 2013;35:1303-7.

55. Blazeck J, Alper HS. Promoter engineering: recent advances in controlling transcription at the most fundamental level. Biotechnol J. 2013;8:46-58.

56. Yamanishi M, Ito Y, Kintaka R, Imamura C, Katahira S, Ikeuchi A, Moriya H, Matsuyama T. A genome-wide activity assessment of terminator regions in Saccharomyces cerevisiae provides a "terminatome" toolbox. ACS Synth Biol. 2013;2:337-47.

57. Ito Y, Yamanishi M, Ikeuchi A, Matsuyama T. A highly tunable system for the simultaneous expression of multiple enzymes in Saccharomyces cerevisiae. ACS Synth Biol. 2014. doi:10.1021/sb500096y.

58. Van Zyl JH, Den Haan R, Van Zyl WH. Over-expression of native Saccharomyces cerevisiae exocytic SNARE genes increased heterologous cellulase secretion. Appl Microbiol Biotechnol. 2014;98:5567-78.

59. Kroukamp H, den Haan R, van Wyk N, van Zyl WH. Overexpression of native PSE1 and SOD1 in Saccharomyces cerevisiae improved heterologous cellulase secretion. Appl Energ. 2013;102:150-6.

60. Garvey M, Klose H, Fischer R, Lambertz C, Commandeur U. Cellulases for biomass degradation: comparing recombinant cellulase expression platforms. Trends Biotechnol. 2013;31:581-93.

61. Wilson DB. Cellulases and biofuels. Curr Opin Biotechnol. 2009;20:295-9.

62. Peterson R, Nevalainen $\mathrm{H}$. Trichoderma reesei RUT-C30 - thirty years of strain improvement. Microbiology. 2012;158:58-68. 
63. Prabu R, Kuila A, Ravishankar R, Rao PVC, Choudary NV, Velankar HR. Microbial rhamnolipid production in wheat straw hydrolysate supplemented with basic salts. RSC Adv. 2015;5:51642.

64. Sluiter A, Hames B, Ruiz R, Scarlata C, Sluiter J, Templeton D, Crocker D. Determination of structural carbohydrates and lignin in biomass. Laboratory analytical procedure. NREL/TP-510-42618 2011.
65. Ghose TK. Measurement of cellulase activities. Pure Appl Chem. 1987:69:257-66.

66. Miller GL. Use of Dinitrosalicylic reagent for determination of reducing sugar. Anal Chem. 1959:39:426-8.

67. Mandels M, Andreotti R, Roche C. Measurement of saccharifying cellulase. Biotechnol Bioeng Symp. 1976;6:21-33.

\section{Submit your next manuscript to BioMed Central} and we will help you at every step:

- We accept pre-submission inquiries

- Our selector tool helps you to find the most relevant journal

- We provide round the clock customer support

- Convenient online submission

- Thorough peer review

- Inclusion in PubMed and all major indexing services

- Maximum visibility for your research

Submit your manuscript at www.biomedcentral com/submit
(O) Biomed Central 